\title{
Past, Present and Future Urban Water: The Challenges in Creating More Beneficial Trajectories
}

Iain White 1 ,

Emailiainw@waikato.ac.nz

1 University of Waikato, Hamilton, New Zealand

\section{Abstract}

Alternative visions of cities that treat water more sustainably are becoming more compelling as understanding increases of current impacts and future pressures. Here, an alternative relationship between water, space and citizens is commonly advocated that represents a significant shift from the technorational supply-oriented emphasis of the twentieth century. In discussions connected to any transition to a more beneficial urban water trajectory, aspects such as land use change, new technologies or innovative policies are frequently held up as being critical elements. Rather than focus on any notional Water Sensitive City as an outcome to be achieved, this chapter complements this literature by critically examining the processes that may help or hinder transitions of this nature. It firstly explores the historical states of urban water management and links to the wider socio-political context within which change must occur. It then analyses issues related to the speed and scale of land use change, emphasising how every urban area has differing flows of finance, regeneration opportunities or free development space. The argument then turns to path dependence and how institutional, cultural and technological norms may resist attempts at change, before focusing on the difficulties in enabling effective policy transfer across what are distinct territories and contexts. It ends with a discussion on how water is just one of an increasing number of competing urban visions - from the Smart City to the Resilient City - all of which are fighting for attention, resources and action.

\subsection{Urban Water: Introducing the Past, Present and Future}

Water has been critical to where cities originate, their development, and the standard of living of their inhabitants. However, the relationship is complex, and in high-income nations it is easy to forget how vital the effective management of the resource is. We need continual availability and protection from its potential impacts: too much or too little water can have devastating consequences. To achieve this delicate balance, for the last 200 years or so water in cities has been predominately managed by a technocentric paradigm. Hard infrastructure places water where society needs it to be - captured and transported to people's homes and businesses, moved swiftly away in drains at times of precipitation, or enclosed behind embankments and walls to prevent damage. This approach has been widely adopted throughout the developed world and has laid the foundation for huge advances in economic growth, health and quality of life.

Yet arguments to rethink this strategy have been gaining in power, particularly over the last two decades, and calls for more sensitive and sustainable water management are becoming increasingly prevalent (Mitchell 2006; Bell 2015; Scott et al. 2013). Although a technocratic emphasis served to solve the arch 
nineteenth century problems of sanitation and water supply that were so closely associated with the emergence of the industrial city, as a corollary it also created the foundation for difficulties in the present that seem to resist easy resolution - from diffuse pollution, to surface water flooding, to expensive infrastructure provision (Douglas et al. 2010; White 2010). Critically, these are all predicted to worsen in the future. From the risks of climate change altering precipitation patterns (Intergovernmental Panel for Climate Change 2014), to rising urban populations (United Nations 2011), to talk of water and wastewater 'infrastructure crises' (Cromwell et al. 2007), it is clear that the future trajectory of urban water is going to be far from smooth and unproblematic. AQ1

It is also apparent that in many circumstances it is the water management orthodoxy itself that has created and is perpetuating these impacts, such as the historical view of water as being more of a hazard to be removed than resource to be retained, or long-standing norms of disciplinary involvement that privilege certain technical approaches. Perhaps counter intuitively, despite huge advances in science, technology, infrastructure and managerial practices, cities on all continents are grappling with water management as a key twenty-first century problem.

In response to a growing awareness of the undesirable impacts of long-held water management regimes, new ideas and concepts are becoming more prevalent. Here, water is increasingly seen as less distinctly separate from the built environment - an 'other' to be controlled - and more an intrinsic part of an urban metabolism; continuously shaping, enabling and producing (Gandy 2004). This metabolic influence can be viewed throughout the various elements of the city, whether in regard to the use of land, the behaviour of citizens, or the opportunity for economic or leisure activities (Heynen et al. 2006). Significantly, this viewpoint goes beyond its functionality and instead acknowledges the wider transformative potential of water: it shapes us, just as much as we shape it.

Emerging in parallel with these new relational understandings are discourses that advocate an alternative ontological view, such as the 'water sensitive city' (Howe and Mitchell 2012; Wong 2006) or 'water sensitive urban design' (Donofrio et al. 2009). Central to these normative perspectives is an engagement with the urban water cycle and increased integration between engineering and ecological professions, with opportunities to redesign the city, change institutional and planning norms, or alter citizen interaction encouraged (Ashley et al. 2013; Carter and White 2012; Wong and Brown 2009). As water management is redefined as a transdisciplinary and integrative issue that has heightened importance in urban decisions, it is anticipated that the wider costs of water will be mitigated and the benefits will be more easily realised. It is important to note that future water visions like these are not necessarily deemed to provide a teleological end point or specific goal that needs to be achieved, rather by highlighting impacts and opportunities they serve to emphasise the need and rationale for change more broadly (Brown 2012). Above all, they persuasively recast water as a valuable resource; one which if managed correctly can bring a wide range of environmental, social and economic advantages to a city.

However, despite emerging critique the predominant managerial regime for urban water has proved remarkably resistant to change. While a host of factors from construction, materials or modelling have been improved, crucially, the overall methodology that frames the management of urban water remains steadfastly instrumental, technical and rational. Indeed, the modern systems in place in most countries today would be readily recognisable to those pioneering water engineers of nineteenth century Paris or London. The approach has also been supported by parallel technical advances in areas such as science, modelling or engineering. As a result, this bespoke expertise is also given a powerful capability and mandate to act, with dedicated agencies and funding streams established to deliver more of the same modes of infrastructure and manage these significant assets to create shareholder value.

It is valuable to take a step back and observe not just how we manage water, but the wider social, economic and institutional aspects that both serve to underpin and perpetuate this approach. As a consequence, despite calls to adopt the principles of a more water sensitive city this has proved a difficult transition as it is not just an infrastructural problem, but rather one embedded in science and society more generally. 
This chapter unpacks how this situation has occurred, examining how actions in the past have created the present relationship between water and urbanity and focuses on the processes that may help or hinder and future transitions. The chapter highlights how resistant to change water management practices have become, being underpinned by historic land uses and scientific approaches, disciplinary silos and governance structures, and locally competing policies and priorities. In recognising that the problems of the present have their seeds in the past, the argument is focused on exploring the issues that may inhibit the ability to generate and normalise a more sustainable urban water future.

\subsection{Contextualising Change: The Journey, Destination and Milieu}

There have been a number of attempts to delineate a typology that is able to succinctly capture and summarise the historical states and trajectories of formalised urban water management since its initial development in the nineteenth century. For example, in a study of Australian cities Brown and her collaborators (2009) identify six states that are presented as operating as a nested continuum. The first three of which, the 'Water Supply City', the 'Sewered City' and the 'Drained City', represent a loosely historical chronological view, while the 'Waterways City', the 'Water Cycle City' and the 'Water Sensitive City', are less readily visible with the last of which being a desirable destination to move towards. They further highlight the importance of 'disturbances' that facilitate innovation, adaptive capacity and the possibility of differing trajectories taking place. Alternatively, Gandy (2004) suggests that the initial public health phase could be clearly considered as akin to a 'bacteriological city', but that distinct typologies since this time they are more difficult to precisely ascertain. Since the late twentieth century political economy aspects such as fragmentary pressures, privatisation trends and shareholder value are all increasingly in evidence and he argues that notions of linear characterisations of discrete transitions between well-defined states have instead become subsumed within a more messy relational and hybridised metabolic system.

These examples are both useful in explaining how perceptions of the water in cities have altered temporally and ideologically. More pertinently to this chapter these twin stances point towards how we can understand the processes of change. Here, the debates in this area tend to be twofold; either a form of solutionfocused urban Darwinism, perhaps incorporating futurist discussion of a utopian state to gradual transition towards, such as demonstrated by the 'Water Sensitive City' (Howe and Mitchell 2012), 'Water Centric Sustainable Community' (Novotny et al. 2010), 'Absorbent City' (White 2008) or a more generalised form of 'Blue Urbanism' (Beatley 2014). On the other hand, discussion focuses on the social and political spheres, where the instrumentalism of urban water infrastructure is considered indivisible from the broader societal contexts within which it operates. From this perspective, developments in capitalism and neoliberalism have shifted the emphasis away from the strong early focus on achieving universalism of supply towards the present configuration where water is routinely seen as a means to produce private profit. As a consequence, the resource - and any possible transition - is redefined as being heavily subjected to politics, conflict and power (Swyngedouw 2004).

Together these literatures offer valuable perspectives for understanding issues connected with urban water trajectories. They highlight how societal expectations change over time, identify a number of possible 'best practice' models to shift towards, and also emphasise the intensely political, economic and cultural arenas within which urban water issues now find themselves. Indeed, the tight links between water and politics have led to urban water being described as operating as a 'sociotechnical system' (Graham and Marvin 2001, p. 8) where a 'hydro-social contract' (Lundqvist et al. 2001, p. 355) can be seen to exist. What is clear is that any discussion of trajectories needs to be positioned within both a discussion of outcomes and a consideration of the processes and milieu within which those may be achieved. In short, any transitions are grounded in the nature of a place.

It is within this context that the following discussion is situated; one where notions of change may be more incremental than fundamental, and where future cities are used as a means to analyse current processes and practices rather than as a distant teleological goal. What is common is that alongside an increased 
understanding of water impacts and pressures, there are consistent calls for a more sustainable shift in urban water systems. However, in addition to the thorny subjects of politics and power, any transformation also needs to occur within a spatial planning context, which is itself highly political. This chapter now turns the discussion towards the realities of enabling land use change of this nature, in particular emphasising how previous decisions and current frameworks offer resistance to meta-narratives that aim to promote thematic urban visions.

\subsection{Exploring Land Use Change: Speed, Scale and Competition}

In debates connected to any transition to a more beneficial water trajectory, a different urban form is frequently held up as being a critical element. Here, an alternative relationship between water, space and citizens is advocated over multiple scales in order to influence demand and supply, or limit wider societal impacts. For example, urban sprawl is a very expensive way to live. Not only does it carry significant economic demands for new infrastructure provision but it locks those costs into future maintenance regimes for decades to come. Therefore, densification is usually recommended as it plugs houses into existing water networks, reduces the need for new infrastructure and limits the wider impact of sprawl on the environment (Spier and Stephenson 2002). Equally, at a smaller spatial scale more sustainable approaches to manage water within the urban area are widely advocated as a means to reduce diffuse pollution (White and Howe 2005; White and Alarcon 2009), as are building scale measures concerning recycling greywater or blackwater on site, or adopting Water Sensitive Urban Design techniques (Wong and Brown 2010). What these aspects all have in common is a desire to control the location and function of development, and to engender new behaviours. They also tend to link to the planning system as the main mechanism able to exert influence over development - but how malleable is the urban form? And how receptive are industries and people to these possible changes? Questions such as these are critical in debates concerning urban water futures as not only may change be resisted, but previous land use decisions have a surprising longevity and stickiness regardless of the desirability of any new plans.

AQ2

A good historic example to illustrate this point concerns the Great Fire of London in 1666. The fire burned over four days, quickly devastating parts of central London and the nature of the urban form played no small role in this. The predominately wood and pitch building materials used were highly flammable, while the labyrinthine design and narrow distance between overhanging buildings both allowed the fire to spread quickly and made access difficult for the citizen fire fighters. The scale of the loss was staggering. It is estimated that around 13,000 homes were destroyed and a huge portion of the city was in need of complete reconstruction (Platt 2004). However, this volume of newly available development space creates opportunities too. The day after the fire was extinguished Sir Christopher Wren proposed a new design for London to King Charles II, one that would create an urban form less susceptible to this particular risk. It was modelled on the wider, grand Boulevards in evidence across much of Europe and provided a striking difference to the compact and twisting medieval pattern in place at the time.

Yet, despite the enormous power of the monarch and the desire for change, Wren's plan was never implemented and the reasons why are exactly the same as why a similar notion to redesign a city would be so difficult to execute in the present: individual property ownership. Simply put, after the flames died down people had the desire and the right to rebuild and carry on as before. Even as far back as 350 years ago, where power was extremely concentrated and where there was a much simpler legislative and political context, plans to transition to a different urban future proved impossible to implement. In the absence of huge state intervention designed to buy up differing plots of land it proved unworkable; the grand scheme could not disregard the context of the burgeoning mercantilism of the time, just as much as we could not discount norms of individual freedoms and capitalism in the current period.

An alternative approach to rapid wholesale change is that of incremental transition as new development and regeneration provides opportunities to gradually reshape and recast the urban form. From this perspective a plan to adopt the principles and practices of a more water sensitive city is a long term objective; not 
just a distant outcome, but also a process or means to influence an array of decisions concerned with water, space and society. There is an inherent logic to this approach, not only does the planning system enable the state to influence development proposals in this manner, but strategic planning elements also allow plans to be consulted, agreed upon and made statutory. Therefore, if a vision was implemented in this manner it should have a mandate and an effect. However, even if this could be achieved there are still a number of factors that could impede the effectiveness of this tactic; most notably the speed and scale of change, and competition over the uses of space associated with capitalism.

With regard to the first of these elements, research detailing the annual rate of all urban change from a city perspective is surprisingly thin on the ground. The rate and spread of urban sprawl receives attention (e.g. Siedentop and Fina 2012). There are also statistics in many countries regarding new homes built, greenspace loss, or land use change from, say, agriculture to residential (see, for example, Department for Communities and Local Government 2014), but these are not necessarily in the specific form that this query demands - which is the overall rate of development churn of new and existing urban areas regardless of formal changes in land designation. Here, for instance, any development provides the ability to influence the relationship between water and society, even if the category of land use remains constant. Yet, even if figures on this topic were available they may not represent a long enough time span, or reflect the dynamism of socio-political pressures, to enable the data set to allow robust judgements to be drawn regarding the speed of any future urban transformation. The paucity of data, therefore, is partly due to the emergent nature of strategic spatial analysis of this nature, which has developed rapidly alongside the increase in computing power and visualisation tools such as Geographical Information Systems, but it is also connected to the difficulty in compiling such information in a way that makes sense.

This leads us onto our second point, as scalar issues would also come to the fore. From the onset, there is an epistemological problem endemic to the field of urban studies more generally concerning where to draw the lines around a settlement to allow easy spatial comparisons. It is just the city, or does it include suburbs, peri-urban areas, or city-regions? It is something connected to metropolitan form or the more functional relations that may not be so easily delineated? New urban terms also evolve, each with their own theoretical, epistemological and ontological frames, casting further doubt over the clarity and specificity of the research object. Over recent years the spatial lexicon continues to gain in sophistication to the extent that it has now been posited as being in an unstable state of continual creation and dissolution, where new post-this and post-that labels jostle alongside the ongoing development of emergent concepts such as Edge Cities or Limitless Cities (Taylor and Lang 2004). This maelstrom of creative destruction goes beyond semantics and instead provides a problematic context within which to consider the feasibility of a stable and long-term transition to any single discrete urban concept.

To compound matters, not only does the potential research object have a tendency to expand its boundaries, but within a city there is huge variation: some areas are incredibly vibrant and experience a high turnover of development proposals, while others languish and remain largely unchanged for decades. Then there are the occasional natural or manufactured shocks, for example the Christchurch earthquake in New Zealand in 2011 or the IRA bomb in Manchester, UK, in 1996, both of which resulted in significant changes to core areas of the city within a very short time and gained huge political momentum of their own regardless of the state of the current plans in place. Simply put, when drawing conclusions regarding the rate of urban change it is hard to generalise due to the vagaries of development, space and capital. Even if ontological clarity is gained on a single vision, every urban area has differing flows of finance, regeneration opportunities, historical protection areas and free space.

While the discussion so far has mainly focused on land use change and the planning system, many of the aims of a more sustainable urban water future do not require planning permission, being connected to elements such as technology uptake, institutional operation or individual behaviour. The argument now explores transitions research connected to these wider institutional, cultural and technological elements. 


\subsection{History Matters: Institutionally, Culturally and Technologically}

This section highlights how any transition to a different urban form is heavily reliant upon a number of wider social, economic and cultural factors, building on the argument that the existence of plans of this nature are no guarantee of tangible progress, never mind success. With regard to technology, for example, the social context is vital to any uptake. Innovation can frequently be resisted by both people and policy-makers, whether because of an uncertainty over costs and performance, a lack of cultural legitimacy, ill-suited legislation, or institutional inertia - all of which can cast doubt on the potential of future technological solutions to solve emerging environmental problems. David (1985) uses the example of the QWERTY keyboard layout to illustrate this argument. This design was originally implemented to slow down manual typewriters, the keys of which had a tendency to stick with high-speed use, but it has continued through to the digital era despite other models being more efficient and easier to master.

A similar point can be made regarding the ability to implement the technological innovations that are frequently mooted as a solution to change the relationship between society and water. Here, new technologies may be championed that can reduce demand or capture water on site. As a result, it may be expected that developers and consumers will gradually move to the preferred approach. One of the problems in this regard is that experts and policy-makers often assume that their interventions are aimed at calculating, rational individuals where the only imperative is to convince people to use them (see Geels and Smit 2000 ). Following this assumption, consumers will make the 'correct' choices, and technology will transfer to practice. In reality, this is far from true. Guy and Shove (2000, p. 10) instead argue that: 'similar technical strategies do and do not make sense for different reasons and at different moments in time, and that their adoption depends on the sometimes competing perspectives and priorities of a whole network of organisational actors. Whatever else, the picture is certainly not one in which proven knowledge is seamlessly transferred from research to practice.' This societal complexity also provides a challenge to the remorseless rationality of neoclassical economics, where people are frequently assumed to act logically in response to market forces, and where more effective solutions will inevitably prevail.

The culture of institutions or decision-making further complicates matters. Water is governed by many differing stakeholders, each with their own perspectives and constraints. While traditionally urban water has predominately been considered as operating squarely within a supply-oriented logic under the auspices of the engineering profession, it is clear that the socio-political context and the temporal aspects of transitioning to an alternative demand-oriented future means that it is also a concern for the social sciences and society more broadly. There may be contrasting frameworks or ways of knowing, which can privilege longheld approaches and resist the new working practices that any transition may demand. For example, norms in infrastructure provision are rooted in modelling, risk and cost-benefit analyses while those concerned with planning and land use change may have a remit for community engagement, more efficient spatial organisation or more intangible notions of place-making (Potter et al. 2011). Perhaps, most unlikely of all given international trends in neoliberalism and capitalism, is a government stance acknowledging urban water as a serious enough issue to warrant unprecedented state intervention in the market or new hybridised forms of governance involving as wide an array of actors and agencies as housing developers, multi-national companies, and individual homeowners. This represents a quandary at the core of anyall public policy initiatives: if plans are without power they may only have limited influence, but if they do then they may be less likely to be implemented.

In transitions literature, institutional, cultural or technological causality problems such as these tend to be neatly encapsulated by the phrase that 'history matters': decisions in the past shape decisions in the present - our path is partly laid (see Peters 2001). Here, parallels with evolution are seen to exist where reversibility is difficult to achieve, and the huge historic investment in infrastructure has effectively served to restrict current investment decisions or ways of working. The notion that future choices are constrained by previous decisions is known as 'path dependence', where system elements such as persistence or durability, normality seen as positive aspects, instead serve to replicate practices (David 2001). Path dependence can be weak or strong and occurs due to experiencing increasing returns from specific practices, and where positive feedback and self-reinforcement combine to 'lock-in' a prevailing trajectory (Page 
2007). We can see how the provision of infrastructure or cultural norms of water use map clearly onto these criteria, but its effects are much more pervasive. For example, in a meta-analysis of factors that can inhibit the ability to deliver sustainable water management, Brown and Farrelly (2009) identified a typology of 12 barrier types, including issues related to community, resources, responsibility, knowledge, vision, commitment and coordination.

A useful aspect of the path dependence perspective is that it highlights how water practices have a deterministic dimension that means change may be actively resisted without enabling aspects such as issue champions or supportive contexts (Brown 2012). Simply put, any future Water Sensitive City is constrained by the means designed to deliver the previous Water Supply City.

\subsection{Policy 'Mobility' and 'Transfer': Internationalisation in Local Contexts}

Any urban water transition will necessarily have to navigate the world of policy; the encompassing and dynamic nature of which can be daunting. A host of socio-spatial initiatives, such as demand strategies, sustainable urban drainage policies and water efficiency targets, may all be in force and operated by a variety of stakeholders, and subject to changes in political emphasis or wholesale replacement as new trends and ideas emerge. The ongoing requirement to design, monitor, integrate and adapt policies, combined with restrictions on staff resources and time, means that policy development frequently takes ideas and proposals from elsewhere and seeks to convert these into local solutions as may be the case with urban water. More sustainable urban water futures are one such proposal, but while best practice, exemplar projects or agenda-setting initiatives can provide enormous assistance, policies that are successful in one place may not be effective in a different social, cultural or political context. The opening of the Guggenheim Museum in Bilbao in northern Spain as a means of driving urban renewal is a case in point. While it is commonly seen internationally as providing the catalyst for significant inward investment and the striking rebranding of the city as a cultural destination, it is a story that is highly unlikely to be replicated elsewhere, being a product of a particular place, time and context rather than an off-the-shelf policy product.

Peck (2003) highlights factors such as the internationalisation of conferences and consultancy firms, and the formation of new transnational institutions and professional networks as enabling and globalizing the policy transfer process. As such, the effective mobility and proliferation of policy ideas between places is much more complex than a simple focus on appropriation and translation. Policy is territorial and relational; being the product of locally dependent interests, actors and agencies, and its mobility can be dependent on as wide a range of issues as the flow of global capital to the local practice of power (McCann and Ward 2011). This situation is made even more complex by considering how global capitalism demands competition; cities and nations vie for investment and attention, creating an ever-capricious policy vogue. In addition to the risk of adopting a 'ready-made' policy that might not be effective in a new locality, the political emphasis on quick results may also lead to a rapid incorporation that can undermine local democratic processes. Perhaps more fundamentally, it can serve to marginalise planning, and its ability to shape local space and place, in favour of a role centred on enacting international policy ideas within a global marketplace.

Further, even after the process of design and implementation, new policies can be subject to resistance. Actors including policy-makers, the business sector and communities may have long-standing frames, routines and practices through which a prevailing system is reproduced and current trajectories resist change past decisions, therefore, can lock actors into particular pathways in a similar vein to that discussed in the previous section. In sum, new practices can also initially be resisted at the level of institutions, technical systems, culture and legislation, which can be path-dependent and require significant reinforcement in social, cultural, economic and technical domains (Geels and Verhees 2011; Simmie 2012). Appreciating the issue of resistance to change and territorial inertia can also be used in a positive manner, however. Here it is desirable to highlight the possibility of creating new and more beneficial pathways, and shedding light on the steps needed to secure their eventual 'lock-in'. This is a significant issue for transitions, as much of the onus is on engendering changes and normalising new practices and behaviours. 
The key message from this section is that any transition towards a more water sensitive city has to occur within local and national social, political and economic circumstances (Brown et al. 2009) - homogeneous policy norms do not map well onto heterogeneous social, political and environmental contexts. While, policy and technology can play a vital role in enabling differing urban water futures, there is a need to recognise that the way we know and represent the world is inseparable from the ways in which we choose to live in it (Jasanoff 2004); knowledge and solutions are embedded in societal contexts, not separate artefacts to be generated and applied. As a consequence, transitions also demand a high degree of coordination, interrogation and adaptation by key stakeholders. This also includes adopting an interdisciplinary collaborative scientific perspective, where, for example, the natural sciences may research catchment behaviour, while the social sciences analyse possible planning and legal mechanisms, taxation regimes or economic incentives.

\subsection{Conclusion: Recognising the Pluralism of Trajectories}

Essentially the question of urban trajectories can be distilled down to advocating an alternative vision of how we use space over time. A more sustainable urban water future considers space in the Euclidian sense connected with how water interacts with the built environment, and adopts a more spatial perspective that has the ability to integrate wider elements such as governance, decision-making and individual behaviour. Appreciating the temporal factors is equally important. For example, even estimating a rate of land use change of between 1 and $3 \%$ per annum, any alteration will take many decades and perhaps even the best part of the twenty-first century. This brings the new danger: if a plan takes this long to implement there is a chance that it will never be fully in place. For instance, Berman (1983, p. 15) argues that a feature of modernity is that it fosters an environment of 'perpetual disintegration', where a host of factors from social processes, to globalisation, to demographic change interact, fluctuate and become superseded. To put it another way, can you think of any city wide plan that was designed in the 1960 s that is both still in operation today and has managed to maintain political momentum, stakeholder engagement and public acceptance throughout this time? It is this argument that provides a key counter to notions that visions could be posited as possible end states. While the idea of a prospective blueprint can be compelling and aid in gathering focus, in reality academic critique is commonly on the poor sustainability of current processes and practices: in this regard prospective urban visions are not necessarily futuristic - an end-state to transition towards - they are a key tool to better understand the present.

While urban change does have a strong influence on water, it should also be recognised that this aspect is just one element of planning, and one that can be very low down on the priority list in comparison to economic growth or housing provision. This is apparent by examining the nature of urban policies in any given city; in reality only those areas that have experienced significant flooding or drought have elevated the agenda to a place where it would have the opportunity to gain precedence over other issues. In addition, to keep pace with the sheer dynamism of contemporary society there has been huge theoretical creativity and conceptual innovation, and, as a result, there has been a veritable explosion of urban labelling to the extent that the confusing taxonomies have been accused of fostering obfuscation rather than illumination (Taylor and Lang 2004). As a consequence, future water visions are also in a conceptual contest with other potential notions of cities, such as the 'Smart City' (Hollands 2008), 'Resilient City' (Vale and Campanella 2005) or 'Just City' (Fainstein 2010) - all of which are fighting for attention, resources and action, and wield their own concepts, ideologies and strategies. More critically, there should also be an acknowledgement that any potential new 'lock-in' as part of a transitional strategy may also need to be 'unlocked' at some point in the future - if there is one thing that is apparent from studying the past, it is that societal requirements can change quickly.

That is not to discount the value of such exercises, however. It should be noted that analysing urban transitions from a pragmatic and practical spatial angle as this chapter has done, does not capture their wider scope and purpose. For example, they are particularly useful in highlighting an urban possibilism and the means by which this could be achieved, they identify wider spatial networks and the roles of key stakeholders, and focus on flaws, inconsistencies and impacts of current norms. It should also be acknowledged that transitions are necessarily pluralistic: it is not simply a choice between a Water Sensitive City or a Smart 
City. There may be multifarious concepts being mooted, all of which have their own trajectories that may not overlap or may even be complementary rather than in direct competition.

In sum, it is argued that discourses erof urban metabolisms or urban water trajectories are implicitly embedded in the nature of the 'urban', as well as the more explicit end vision or discussion of policy, process or practice. As such, from a more abstract perspective any new urban vision such as this reveals itself to be a strong cultural signifier that casts light not just on the relationship between water and society, but rather connects to a deeper narrative on the kinds of societies we would like to inhabit in the future.

\section{References}

Ashley R, Lundy L, Ward S, Shaffer P, Walker L, Morgan C, Saul A, Wong T, Moore S (2013) Water-sensitive design: opportunities for the UK. In: Proceedings of the Institution of Civil Engineers, Municipal Engineer, June, 166 (ME2). pp 65-76

Beatley T (2014) Blue urbanism. Island Press, Washington, DC

Bell SJ (2015) Renegotiating urban water. Prog Plan 96:1-28

Berman M (1983) All that is solid melts into air: the experience of modernity. Verso, London

Brown R (2012) Transitioning to the water sensitive city: the socio-technical challenge. In: Howe C, Mitchell C (eds) Water sensitive cities. IWA Publishing, London, pp 29-42

Brown RR, Farrelly MA (2009) Delivering sustainable urban water management: a review of the hurdles we face. Water Sci Technol 59(5):839-846

Brown RR, Keath N, Wong THF (2009) Urban water management in cities: historical, current and future regimes. Water Sci Technol 59(5):847-855

Carter J, White I (2012) Environmental planning and management in an age of uncertainty: the case of the water framework directive. J Environ Manage 113:228-236

Cromwell JE, Speranza E, Reynolds H (2007) The infrastructure 'Crisis'? Am Water Work Assoc J 99(4):109-115

David PA (1985) Clio and the economics of QWERTY. Am Econ Rev 75(20):332-337

David PA (2001) Path dependence, its critics and the quest for 'historical economics'. In: Garrouste P, Ioannides S (eds) Evolution and path dependence in economic ideas. Edward Elgar, Cheltenham, pp 15-40 
Department for Communities and Local Government (2014) Live tables on land use change statistics. Available at: https://www.gov.uk/government/statisticaldata-sets/live-tables-on-land-use-change-statistics . Accessed 28 Nov 2014

Donofrio J, Kuhn Y, McWalter K, Winsor M (2009) Water-sensitive urban design: an emerging model in sustainable design and comprehensive water-cycle management. Environ Pract 11(03):179-189

Douglas I, Garvin S, Lawson N, Richards J, Tippett J, White I (2010) Urban pluvial flooding: a qualitative case study of cause, effect and non-structural mitigation. J Flood Risk Manag 3:112-125

Fainstein SS (2010) The just city. Cornell University Press, New York

Gandy M (2004) Rethinking urban metabolism: water, space and the modern city. City 8(3):363-379

Geels FW, Smit WA (2000) Failed technology futures: pitfalls and lessons from a historical survey. Futures 32:867-885

Geels FW, Verhees B (2011) Cultural legitimacy and framing struggles in innovation journeys: a cultural-performative perspective and a case study of Dutch nuclear energy (1945-1986). Technol Forecast Soc Change 78:910-930

Graham S, Marvin S (2001) Splintering urbanism: networked infrastructures, technological mobilities. Routledge, London

Guy S, Shove E (2000) The sociology of energy, buildings and the environment: constructing knowledge, designing practice. Routledge, London

Heynen N, Kaika M, Swyngedouw E (2006) In the nature of cities: urban political ecology and the politics of urban metabolism. Routledge, Abingdon

Hollands RG (2008) Will the real smart city please stand up? Intelligent, progressive or entrepreneurial? City 12(3):303-320

Howe C, Mitchell C (2012) Water sensitive cities. IWA Publishing, London

Intergovernmental Panel for Climate Change (2014) Climate change 2014: synthesis report. http://www.ipcc.ch/report/ar5/syr/ . Accessed 3 Nov 2015

Jasanoff S (ed) (2004) States of knowledge: the co-production of science and social order. Routledge, London

Lundqvist J, Turton A, Narain S (2001) Social, institutional and regulatory issues. In: Maksimovic A, Tejeda-Guilbert JA (eds) Frontiers in water management: deadlock or hope. IWA Publishing, Cornwall, pp 344-398

McCann E, Ward K (eds) (2011) Mobile urbanism: cities and policymaking in the global age. University of Minnesota Press, Minneapolis 
Mitchell VG (2006) Applying integrated urban water management concepts: a review of Australian experience. Environ Manag 37(5):589-605

Novotny V, Ahern J, Brown P (2010) Water centric sustainable communities. Wiley, New Jersey

Page SE (2007) Path dependence. Q J Polit Sci 1:87-115

Peck J (2003) Geography and public policy: mapping the penal state. Prog Hum Geogr 27:222-232

Peters BG (2001) Institutional theory in political science. Continuum, London

Platt RH (2004) Land use and society: geography, law, and public policy. Island Press, Washington, DC

Potter K, Ward S, Shaw D, Macdonald N, White I, Butler D, Kellagher R (2011) Engineers and planners - the role of partnerships in pursuing sustainable water management objectives. Eng Sustain 164:239-247

Scott M, White I, Kuhlicke C, Steinführer A, Sultana P, Thompson P, Minnery J, O’Neill E (2013) Living with flood risk. Plan Theor Pract 14(1):103-140

Siedentop S, Fina S (2012) Who sprawls most? Exploring the patterns of urban growth across 26 European countries. Environ Plan B 44:2765-2784

Simmie J (2012) Path dependence and new technological path creation in the Danish wind power Industry. Eur Plan Stud 20:753-772

Spier C, Stephenson K (2002) Does sprawl cost us all? Isolating the effects of housing patterns on public water and sewer costs. J Am Plann Assoc 68(1):56-70

Swyngedouw E (2004) Social power and the urbanization of water. Oxford University Press, Oxford

Taylor PJ, Lang RE (2004) The shock of the new: 100 concepts describing recent urban change. Environ Plan A 36(6):951-995

United Nations (2011) World population prospects: the 2010 revision. United Nations, New York

Vale LJ, Campanella TJ (2005) The Resilient City: how modern cities recover from disaster. Oxford University Press, Oxford

White I (2008) The absorbent city: urban form and flood risk management. In: Proceedings of the Institution of Civil Engineers. Urban Design and Planning, December (DP4), pp 151-161

White I (2010) Water and the city: risk, resilience and planning for a sustainable future. Routledge, London

White I, Alarcon A (2009) Planning policy, sustainable drainage and surface water management: a case study of greater Manchester, UK. Built Environ http://eproofing.springer.com/books/printpage.php?token=e2cL0c47D_nRicr9YAMV089SE4oYI_Pfe7Xs3XVAvoQ 
35(4):516-530

White I, Howe J (2005) Unpacking barriers to sustainable urban drainage use. J Environ Policy Plan 7(1):27-43

Wong T (2006) An overview of water sensitive urban design practices in Australia. Water Pract Technol 1(1):9-16

Wong T, Brown R (2009) The water sensitive city: principles for practice. Water Sci Technol 60(3):673-682 